\title{
Increased gait variability during robot- assisted walking is accompanied by increased sensorimotor brain activity in healthy people
}

Alisa Berger $^{1 *}$ D, Fabian Horst ${ }^{2}$, Fabian Steinberg ${ }^{1,3}$, Fabian Thomas $^{1}$, Claudia Müller-Eising ${ }^{4}$, Wolfgang I. Schöllhorn ${ }^{2}$ and Michael Doppelmayr ${ }^{1,5}$

\begin{abstract}
Background: Gait disorders are major symptoms of neurological diseases affecting the quality of life. Interventions that restore walking and allow patients to maintain safe and independent mobility are essential. Robot-assisted gait training (RAGT) proved to be a promising treatment for restoring and improving the ability to walk. Due to heterogenuous study designs and fragmentary knowlegde about the neural correlates associated with RAGT and the relation to motor recovery, guidelines for an individually optimized therapy can hardly be derived. To optimize robotic rehabilitation, it is crucial to understand how robotic assistance affect locomotor control and its underlying brain activity. Thus, this study aimed to investigate the effects of robotic assistance (RA) during treadmill walking (TW) on cortical activity and the relationship between RA-related changes of cortical activity and biomechanical gait characteristics.
\end{abstract}

Methods: Twelve healthy, right-handed volunteers ( 9 females; $M=25 \pm 4$ years) performed unassisted walking (UAW) and robot-assisted walking (RAW) trials on a treadmill, at $2.8 \mathrm{~km} / \mathrm{h}$, in a randomized, within-subject design. Ground reaction forces (GRFs) provided information regarding the individual gait patterns, while brain activity was examined by measuring cerebral hemodynamic changes in brain regions associated with the cortical locomotor network, including the sensorimotor cortex (SMC), premotor cortex (PMC) and supplementary motor area (SMA), using functional near-infrared spectroscopy (fNIRS).

Results: A statistically significant increase in brain activity was observed in the SMC compared with the PMC and SMA $(p<0.05)$, and a classical double bump in the vertical GRF was observed during both UAW and RAW throughout the stance phase. However, intraindividual gait variability increased significantly with RA and was correlated with increased brain activity in the SMC $(p=0.05 ; r=0.57)$.

(Continued on next page)

\footnotetext{
* Correspondence: alisa.berger@uni-mainz.de

${ }^{1}$ Department of Sport Psychology, Institute of Sport Science, Johannes Gutenberg-University Mainz, Albert Schweitzer Straße 22, 55128 Mainz, Germany

Full list of author information is available at the end of the article
}

(C) The Author(s). 2019 Open Access This article is distributed under the terms of the Creative Commons Attribution 4.0 International License (http://creativecommons.org/licenses/by/4.0/), which permits unrestricted use, distribution, and reproduction in any medium, provided you give appropriate credit to the original author(s) and the source, provide a link to the Creative Commons license, and indicate if changes were made. The Creative Commons Public Domain Dedication waiver (http://creativecommons.org/publicdomain/zero/1.0/) applies to the data made available in this article, unless otherwise stated. 
(Continued from previous page)

Conclusions: On the one hand, robotic guidance could generate sensory feedback that promotes active participation, leading to increased gait variability and somatosensory brain activity. On the other hand, changes in brain activity and biomechanical gait characteristics may also be due to the sensory feedback of the robot, which disrupts the cortical network of automated walking in healthy individuals. More comprehensive neurophysiological studies both in laboratory and in clinical settings are necessary to investigate the entire brain network associated with RAW.

Keywords: Walking, Gait variability, GRF, Brain activity, Neuroimaging, Functional near-infrared spectroscopy, fNIRS, Robotic rehabilitation, RAGT, Neurorehabilitation

\section{Background}

Safe and independent locomotion represents a fundamental motor function for humans that is essential for self-contained living and good quality of life [1-5]. Locomotion requires the ability to coordinate a number of different muscles acting on different joints [6-8], which are guided by cortical and subcortical brain structures within the locomotor network [9]. Structural and functional changes within the locomotor network are often accompanied by gait and balance impairments which are frequently considered to be the most significant concerns in individuals suffering from brain injuries or neurological diseases $[5,10,11]$. Reduced walking speeds and step lengths [12] as well as non-optimal amount of gait variability [13-15] are common symptoms associated with gait impairments that increase the risk of falling [16].

In addition to manual-assisted therapy, robotic neurorehabilitation has often been applied in recent years $[17,18]$ because it provides early, intensive, taskspecific and multi-sensory training which is thought to be effective for balance and gait recovery [17, 19, 20]. Depending on the severity of the disease, movements can be completely guided or assisted, tailored to individual needs [17], using either stationary robotic systems or wearable powered exoskeletons.

Previous studies investigated the effectiveness of robot-assisted gait training (RAGT) in patients suffering from stroke [21, 22], multiple sclerosis [23-26], Parkinson's disease [27, 28], traumatic brain injury [29] or spinal cord injury [30-32]. Positive effects of RAGT on walking speed [33, 34], leg muscle force [23] step length, and gait symmetry $[29,35]$ were reported. However, the results of different studies are difficult to summarize due to the lack of consistency in protocols and settings of robotic-assisted treatments (e.g., amount and frequency of training sessions, amount and type of provided robotic support) as well as fragmentary knowledge of the effects on functional brain reorganization, motor recovery and their relation [36, 37]. Therefore, it is currently a huge challenge to draw guidelines for robotic rehabilitation protocols [22, 36-38]. To design prologned personalized training protocols in robotic rehabilitation to maximize individual treatment effects [37], it is crucial to increase the understanding of changes in locomotor patterns [39] and brain signals [40] underlying RAGT and how they are related $[36,41]$.

A series of studies investigated the effects of robotic assistance (RA) on biomechanical gait patterns in healthy people [39, 42-44]. On one side, altered gait patterns were reported during robot-assisted walking (RAW) compared to unassisted walking (UAW), in particular, substantially higher muscle activity in the quadriceps, gluteus and adductor longus leg muscles and lower muscle activity in the gastrocnemius and tibialis anterior ankle muscles $[39,42]$ as well as reduced lower-body joint angles due to the little medial-lateral hip movements [45-47]. On the other side, similar muscle activation patterns were observed during RAW compared to UAW [44, 48, 49], indicating that robotic devices allow physiological muscle activation patterns during gait [48]. However, it is hypothesized that the ability to execute a physiological gait pattern depends on how the training parameters such as body weight support (BWS), guidance force (GF) or kinematic restrictions in the robotic devices are set $[44,48,50]$. For example, Aurich-Schuler et al. [48] reported that the movements of the trunk and pelvis are more similar to UAW on a treadmill when the pelvis is not fixed during RAW, indicating that differences in musle activity and kinematic gait characteristics between RAW and UAW are due to the reduction in degrees of freedom that user's experience while walking in the robotic device [45]. In line with this, a clinical concern that is often raised with respect to RAW is the lack of gait variability $[45,48,50]$. It is assumed that since the robotic systems are often operated with $100 \%$ GF, which means that the devices attempt to force a particular gait pattern regardless of the user's intentions, the user lacks the ability to vary and adapt his gait patterns [45]. Contrary to this, Hidler et al. [45] observed differences in kinematic gait patterns between subsequent steps during RAW, as demonstrated by 
variability in relative knee and hip movements. Nevertheless, Gizzi et al. [49] showed that the muscular activity during RAW was clearly more stereotyped and similar among individuals compared to UAW. They concluded that RAW provides a therapeutic approach to restore and improve walking that is more repeatable and standardized than approaches based on exercising during UAW [49].

In addition to biomechanical gait changes, insights into brain activity and intervention-related changes in brain activity that relate to gait responses, will contribute to the optimization of therapy interventions [41, 51]. Whereas the application of functional magnetic resonance imaging (fMRI), considered as gold standard for the assessment of activity in cortical and subcortical structures, is restricted due to the vulnerability for movement artifacts and the range of motion in the scanner [52], functional near infrared spectroscopy (fNIRS) is affordable and easily implementable in a portable system, less susceptible to motion artifacts, thus facilitation a wider range of application with special cohorts (e.g., children, patients) and in everyday environments (e.g., during a therapeutic session of RAW or UAW) $[53,54]$. Although with lower resolution compared to fMRI [55], fNIRS also relies on the principle of neurovascular coupling and allows the indirect evaluation of cortical activation $[56,57]$ based on hemodynamic changes which are analogous to the blood-oxygenation-level-dependent responses measured by fMRI [56]. Despite limited depth sensitivity, which restricts the measurement of brain activity to cortical layers, it is a promising tool to investigate the contribution of cortical areas to the neuromotor control of gross motor skills, such as walking [53]. Regarding the cortical correlates of walking, numerous studies identified either increaesed oxygenated hemoglobin (Hboxy) concentration changes in the sensorimotor cortex (SMC) by using fNIRS [53, 57-59] or suppressed alpha and beta power in sensorimotor areas by using electroencephalography (EEG) [60-62] demonstrating that motor cortex and corticospinal tract contribute directly to the muscle activity of locomotion [63]. However, brain activity during RAW [36, 61, 64-68], especially in patients $[69,70]$ or by using fNIRS $[68,69]$, is rarely studied [71].

Analyzing the effects of RA on brain activity in healthy volunteers, Knaepen et al. [36] reported significantly suppressed alpha and beta rhythms in the right sensory cortex during UAW compared to RAW with $100 \%$ GF and $0 \%$ BWS. Thus, significantly larger involvement of the SMC during UAW compared to RAW were concluded [36]. In contrast, increases of Hboxy were observed in motor areas during RAW compared UAW, leading to the conclusion that RA facilitated increased cortical activation within locomotor control systems
[68]. Furthermore, Simis et al. [69] demonstrated the feasibility of fNIRS to evaluate the real-time activation of the primary motor cortex (M1) in both hemispheres during RAW in patients suffering from spinal cord injury. Two out of three patients exhibited enhanced M1 activation during RAW compared with standing which indicate the enhanced involvement of motor cortical areas in walking with RA [69].

To summarize, previous studies mostly focused the effects of RA on either gait characteristics or brain activity. Combined measurements investigating the effects of RA on both biomechanical and hemodynamic patterns might help for a better understanding of the neurophysiological mechanisms underlying gait and gait disorders as well as the effectiveness of robotic rehabilitation on motor recovery $[37,71]$. Up to now, no consensus exists regarding how robotic devices should be designed, controlled or adjusted (i.e., device settings, such as the level of support) for synergistic interactions with the human body to achieve optimal neurorehabilitation [37, 72]. Therefore, further research concerning behavioral and neurophysiological mechanisms underlying RAW as well as the modulatory effect of RAGT on neuroplasticy and gait recovery are required giving the fact that such knowledge is of clinical relevance for the development of gait rehabilitation strategies.

Consequently, the central purpose of this study was to investigate both gait characteristics and hemodynamic activity during RAW to identify RAWrelated changes in brain activity and their relationship to gait responses. Assuming that sensorimotor areas play a pivotal role within the cortical network of automatic gait $[9,53]$ and that RA affects gait and brain patterns in young, healthy volunteers [39, 42, 45, 68], we hypothesized that RA result in both altered gait and brain activity patterns. Based on previous studies, more stereotypical gait characteristics with less inter- and intraindividual variability are expected during RAW due to $100 \%$ GF and the fixed pelvis compared to UAW [45, 48], wheares brain activity in SMC can be either decreased [36] or increased [68].

\section{Methods}

This study was performed in accordance with the Declaration of Helsinki. Experimental procedures were performed in accordance with the recommendations of the Deutsche Gesellschaft für Psychologie and were approved by the ethical committee of the Medical Association Hessen in Frankfurt (Germany). The participants were informed about all relevant study-related contents and gave their written consent prior to the initiation of the experiment. 


\section{Participants}

Twelve healthy subjects ( 9 female, 3 male; aged $25 \pm 4$ years), without any gait pathologies and free of extremity injuries, were recruited to participate in this study. All participants were right-handed, according to the Edinburg handedness-scale [73], without any neurological or psychological disorders and with normal or correctedto-normal vision. All participants were requested to disclose pre-existing neurological and psychological conditions, medical conditions, drug intake, and alcohol or caffeine intake during the preceding week.

\section{Experimental equipment}

The Lokomat (Hocoma AG, Volketswil, Switzerland) is a robotic gait-orthosis, consisting of a motorized treadmill and a BWS system. Two robotic actuators can guide the knee and hip joints of participants to match preprogrammed gait patterns, which were derived from average joint trajectories of healthy walkers, using a GF ranging from 0 to $100 \%[74,75]$ (Fig. 1a). Kinematic trajectories can be adjusted to each individual's size and step preferences [45]. The BWS was adjusted to $30 \%$ body weight for each participant, and the control mode was set to provide $100 \%$ guidance [64].

Functional activation of the human cerebral cortex was recorded using a near-infrared optical tomographic imaging device (NIRSport, NIRx, Germany; Wavelengths: $760 \mathrm{~nm}, 850 \mathrm{~nm}$; Sampling rate: $7.81 \mathrm{~Hz}$ ). The methodology and the underlying physiology are explained in detail elsewhere [76]. A total of 16 optodes (8 emittors, 8 detectors) were placed with an interoptode distance of $3 \mathrm{~cm}[53,54]$ above the motor cortex, based on the landmarks from the international 10-5 EEG system [77], resulting in 24 channels (source-detector pairs) of measurement (Fig. 1b). The spatial reolution was up to $1 \mathrm{~cm}$. Head dimensions were individually measured and corresponding cap sizes assigned. Channel positions covered identical regions of both hemispheres including the SMC (Brodmann Area [BA] 1-4), and the supplementary motor area/premotor cortex (SMA/PMC; BA6) (Fig. 1c).

Participants were equipped with standardized running shoes (Saucony Ride 9, Saucony, USA). Pressure insoles (Pedar mobile system, Novel GmbH, Germany) were inserted into the shoes for the synchronized measurement of plantar foot pressure, at a frequency of $100 \mathrm{~Hz}$. Each insole consists of 99 capacitive sensors and covers the entire plantar area. The data recording process was managed by the software Novel Pedar-X Recorder 25.6.3 (Novel GmbH, Germany), and the vertical ground reaction force (GRF) was estimated for the analysis of kinetic and temporal gait variables.

\section{Experimental design}

Participants performed two blocks, (1) UAW and (2) RAW, in a randomized order. Each block consisted of five walking trials $(60 \mathrm{~s})$ and intertrail standing intervals of $60 \mathrm{~s}$ (s) [41, 53, 68, 78] (Fig. 2). While walking, the participants were instructed to actively follow the orthosis's guidance while watching a neutral symbol (black cross) on a screen at eye level to ensure the most natural walking possible in an upright posture. During standing (rest), participants were instructed to stand with their feet shoulder-width apart while watching the same black
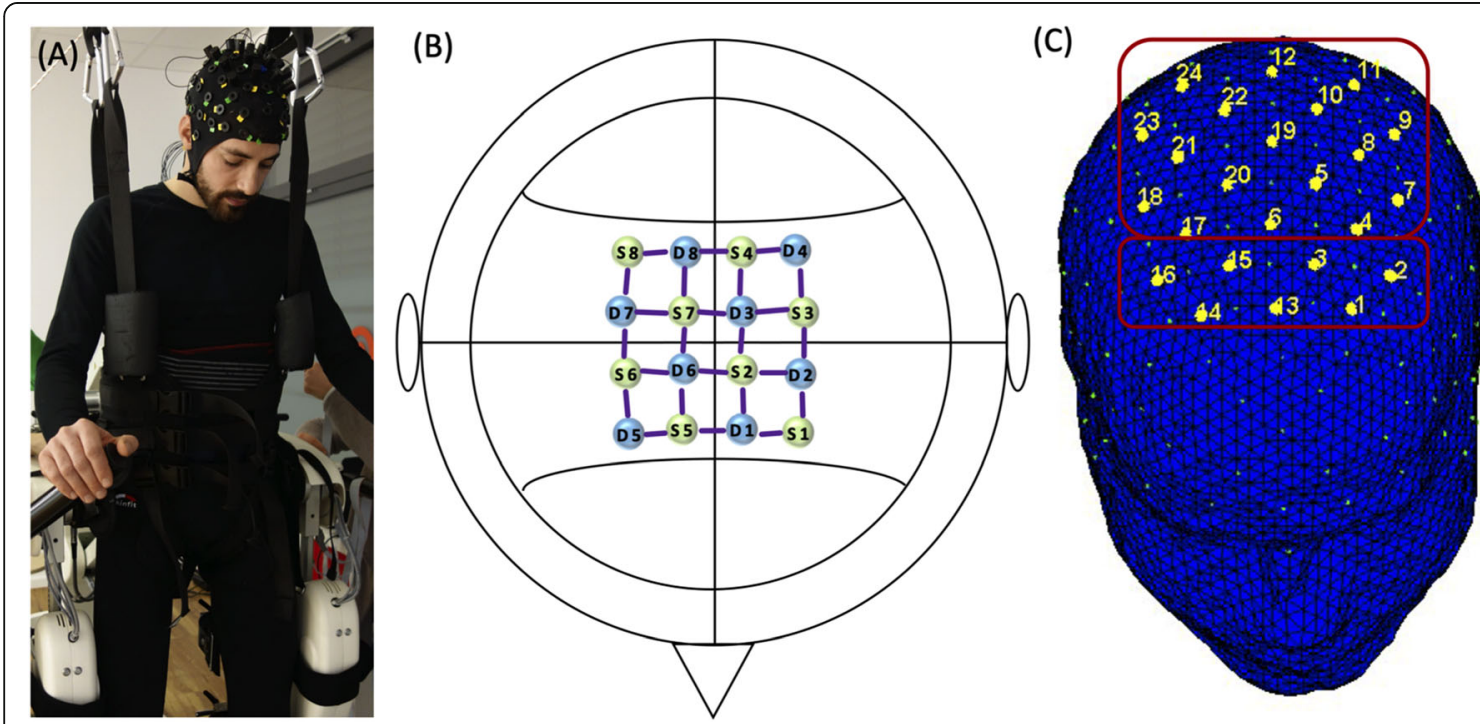

\section{SMC}

(BA 1-4)

SMA/PMC

(BA 6)

Fig. 1 Montage and Setup. a Participant during robot-assisted walking (RAW), with functional near-infrared spectroscopy (fNIRS) montage. b fNIRS montage; $S=$ Sources; $D=$ Detectors c Classification of regions of interest (ROI): supplementary motor area/premotor cortex (SMA/PMC) and sensorimotor cortex (SMC) 


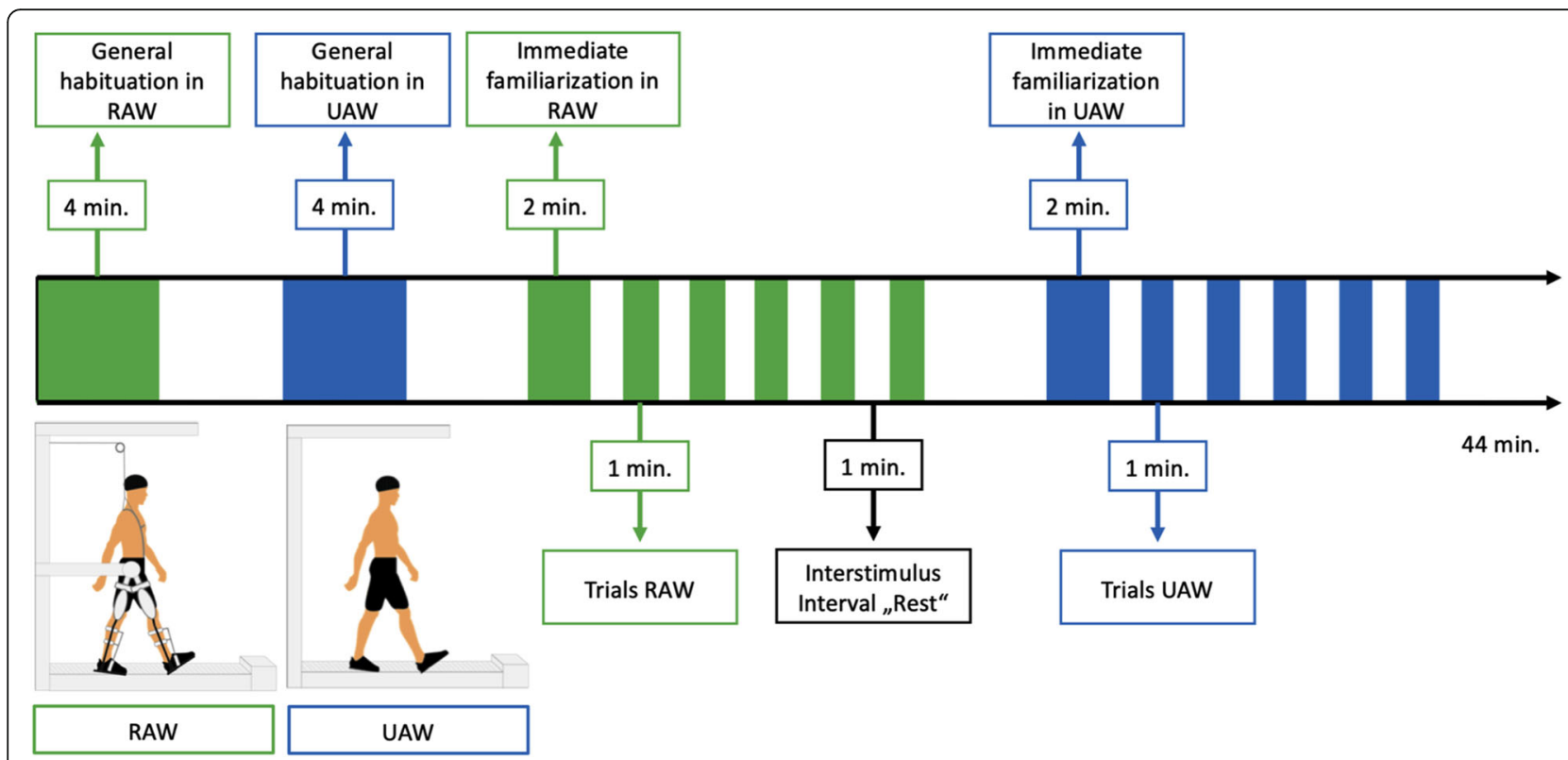

Fig. 2 Study design and schematic illustration of unassisted walking (UAW) and robot-assisted walking (RAW)

cross. Furthermore, the participants were requested to avoid head movements and talking during the entire experiment, to reduce motion and physiological artifacts [78]. Prior to the experiment, individual adjustments of the Lokomat were undertaken, according to common practices in clinical therapy. The safety procedures of the rehabilitation center required that all subjects wore straps around the front foot to assist with ankle dorsiflexion. To familiarize themselves with the robotic device and treadmill walking (TW), participants walked with and without the Lokomat for $4 \mathrm{~min}$ before the experiment started.

\section{Data processing and analysis}

fNIRS raw data were preprocessed and analyzed using the time series analysis routine available in the MATLAB-based NIRSlab analysis package (v2017.05, Nirx Medical Technologies, Glen Head, NY, ["Biomedical Optics"]) [79] following current recommendations when possible [53, 78]. In each channel of individual participant, fNIRS signal was visually inspected with respect to transient spikes and abrupt discontinuities which represent two most common forms of movement artifacts in fNIRS data. First, sections containing discontinuities (or "jumps") as well as long term drifts were detected and corrected (standard deviation threshold $=5$ ) [79]. Second, spikes were smoothed by a procedure that replaces contaminated data with the nearest signal [79]. Third, a band-pass filter $(0.01$ to $0.2 \mathrm{~Hz})$ was applied to attenuate slow drifts and high frequency noises to reduce unknown global trend due to breathing, respiratory or cardiac rhythms, vasomotion, or other movement artifacts [59]. Then, time series of hemodynamic states of Hboxy and deoxygenated hemoglobin (Hbdeoxy) were computed using the the modified Beer-Lambert law [80, 81]. Following parameters were specified: wavelengths $(\mathrm{WL} 1=760 \mathrm{~nm} ; \mathrm{WL} 2=850 \mathrm{~nm})$, differential pathlength factors (7.25 for WL1; 6.38 for WL2), interoptode distances $(3 \mathrm{~cm}$ ), background tissue values (totHb: $75 \mathrm{uM}$; MVO2Sat: 70\%).

Preprocessed Hboxy concentration changes ( $\Delta$ Hboxy) were exported and processed as follows: 50 s per walking trial were used to analyze the hemodynamic responses during (1) UAW and (2) RAW due to the time needed for the acceleration and deceleration of the treadmill. The averaged baseline concentration values of rest before each walking trial were subtracted from the taskevoked concentration measurements, to account for time-dependent changes in cerebral oxygenation [78]. $\Delta$ Hboxy were calculated for regions of interest (ROI) (see Fig. 1c) during both UAW and RAW and used as a marker for the regional cortical activation, since it is more sensitive to locomotion-related activities than Hbdeoxy [82] and represents an accurate indicator of hemodynamic activity [83].

GRFs were preprocessed and analyzed using Matlab 2017b (MathWorks, USA). GRFs were filtered using a second-order Butterworth bidirectional low-pass filter, at a cut off frequency of $30 \mathrm{~Hz}$. Offline processing included kinetic and temporal variables that were calculated based on stance-phase detection, using a GRF threshold of $50 \mathrm{~N}$. The first and last ten stance phases (steps) from each of the five walking trials were excluded from the analysis because they corresponded 
with the acceleration and deceleration phases of the treadmill. The swing and stance phase times were measured. The stance phase was also subdivided into initial double-limb, single-limb and terminal doublelimb support times. Furthermore, the number of steps and the cadence was calculated. Kinetic variables were analyzed during the stance phase of walking. The GRF values were normalized against body mass and were time-normalized against 101 data points corresponding with the stance phase of walking. Gait variability was estimated for time-continuous GRF during the stance phase, using the coefficient of variation (CV) [84]. According to Eq. (1), the intraindividual $\mathrm{CV}$ was calculated based on the mean $\left(\overline{G R F_{s, b, i}}\right)$ and standard deviation $\left(\sigma_{s, b}, i\right)$ of the normalized GRF at the $i$-th interval of a concanated vector of the right and left leg stance phases. The intraindividual CV was calculated for each subject $s$ and both blocks $b$ (RAW and UAW).

$$
\text { IntraindividualCV }(s, b)=\frac{\sqrt{\frac{1}{202} * \sum_{i=1}^{202} \sigma_{s, b, i}{ }^{2}}}{\frac{1}{202} * \sum_{i=1}^{202} \mid \overline{G R F_{s, b, i} \mid}} * 100[\%]
$$

Similarly, interindividual variability was estimated across the subject's mean GRF, calculated across the time-continuous GRF from all stance phases from one subject. According to Eq. (2), the interindividual CV was calculated based on the mean $\left(\overline{G R F_{\bar{s}, b, i}}\right)$ and standard deviation $\left(\sigma_{\bar{s}, b, i}\right)$ of the normalized subject's mean GRF at the $i$-th interval of the concanated vector of the right and left leg stance phases. Interindividual $\mathrm{CV}$ was calculated for both blocks $b$ (RAW and $\mathrm{UAW})$.

$$
\text { InterindividualC } V(b)=\frac{\sqrt{\frac{1}{202} * \sum_{i=1}^{202} \sigma_{\bar{s}, b, i}{ }^{2}}}{\frac{1}{202} * \sum_{i=1}^{202} \mid \overline{G R F_{\bar{s}, b, i} \mid}} * 100[\%]
$$

The absolute magnitude of the symmetry index, according to Herzog et al. [85], was adapted for $i$ timeintervals of time-continuous GRF. The symmetry index (SI) is a method of assessing the differences between the variables associated with both lower limbs during walking. According to Eq. (3), the SI was calculated based on the absolute difference of the mean normalized GRF ( $\overline{G R F_{\_} \text {right }_{i}}$ and $\left.\overline{\text { GRF_left }_{i}}\right)$ at the $i$-th interval for each subject $s$ and both blocks $b$ (RAW and UAW). An SI value of $0 \%$ indicates full symmetry, while an SI value $>0 \%$ indicates the degree of asymmetry [85].

$$
S I(s, b)=\frac{1}{101} *\left(\sum_{i=1}^{101} \frac{\mid \overline{G R F_{\text {right }_{s, b i}}}-\overline{G R F_{\text {left }_{s, b i}} \mid}}{\frac{1}{2} * \mid \overline{G R F_{\text {right }_{s, b, i}}}+\overline{G R F_{\text {left }_{s, b i}} \mid}} * 100\right)[\%]
$$

Based on the time-continuous vertical GRF waveforms, three time-discrete variables were derived within the stance phase: the magnitude of the first peak (weight acceptance), the valley (mid-stance) and the magnitude of the second peak (push-off), as well as their temporal appearances during the stance phase.

The statistical analysis was conducted using SPSS 23 (IBM, Armonk, New York, USA). Normal distribution was examined for both hemodynamic and kinetic/temporal variables using the Shapiro-Wilk test $(p \geq 0.05)$. Averaged Hboxy values were computed for each subject and ROI (SMA/PMC, SMC) during both UAW and RAW [53, 78] and were normalized (normHboxy) by dividing them by the corresponding signal amplitude for the whole experiment [41, 59]. A two-way analysis of variance (ANOVA), with the factors condition (UAW or RAW) and ROI (SMA/PMC, SMC), was used to analyze differences in cortical hemodynamic patterns. In cases of significant main effects, Bonferroni-adjusted post hoc analyses provided statistical information regarding the differences among the ROIs by condition. Temporal and kinetic gait variables were statistically tested for differences between the experimental conditions (UAW and RAW) using paired t-tests. The overall level of significance was set to $p \leq 0.05$. Mauchly's test was used to check for any violations of sphericity. If a violation of sphericity was detected $(p<0.05)$ and a GreenhouseGeisser epsilon $\varepsilon>0.75$ existed, the Huynh-Feldt corrected $p$-values were reported. Otherwise (epsilon $\varepsilon<$ $0.75)$, a Greenhouse-Geisser correction was applied. Effect sizes were given in partial eta-squared $\left(n \mathrm{p}^{2}\right)$ or interpreted, according to Cohen. The association between cortical activation and gait characteristics was explored using Pearson's correlation coefficient.

\section{Results}

\section{Cortical activity (Hboxy)}

The effect of RAW on $\Delta$ Hboxy in locomotor cortical areas was analyzed using a two-way repeated measurements ANOVA with the factors ROI (SMA/PMC, SMC) and CONDITION (UAW, RAW). $\triangle$ Hboxy served as dependent variable. A significant main effect for ROI $\left[\mathrm{F}(1,11)=11.610, p=0.006, \mathrm{np}^{2}=0.513\right]$ was found indicating significant greater $\Delta$ Hboxy values in the 7 channels (1-3,13-16) covering regions of the SMA/PMC [BA6] compared to the 17 channels (4-12 and 17-24) covering regions of the SMC [BA1-4] $(p=0.052)$, independent of the condition. Neither CONDITION $[\mathrm{F}(1$, $\left.11)=1.204, p=0.296, \eta p^{2}=0.099\right]$ nor the interaction 
ROI x CONDITION $\left[\mathrm{F}(1,11)=0.092, p=0.767, \eta^{2}=\right.$ 0.008] were significant (Fig. 3).

\section{Gait characteristics}

Descriptive analyses of the mean vertical GRFs show a "classical" double bump (M-Shape) during the stance phase [84] for both UAW and RAW (Fig. 4). However, various differences in the gait characteristics were observed between the two conditions. First, the mean vertical GRFs were lower during RAW than during UAW. Second, the relative appearance of the peak values occurs earlier for the first peak and later for the second peak during RAW compared with UAW. Third, the vertical GRFs had higher standard deviations during RAW than during UAW. Statistical analyses of the timediscrete kinetic gait variables confirmed significantly lower GRFs and earlier and later appearances for the first and second vertical GRF peaks, respectively, during RAW than during UAW (Table 1).

Fourth, significantly increased inter- and intraindividual variability and asymmetry between the timecontinuous GRFs of the right and left feet (SI values) and significantly longer stance and swing phases emerge during RAW compared with UAW, despite the guidance of the robotic device and the same treadmill velocity (Table 2). Accordingly, lower numbers of steps and lower cadence values were observed during RAW than during UAW.

\section{Association between changes in cortical activity and gait characteristics}

Correlation analyses showed that changes in gait characteristics due to RA were also associated with changes in cortical activity. During RAW, a positive association between gait variability and Hboxy was observed only in the SMC $(p=0.052, r=0.570)$. No further correlations

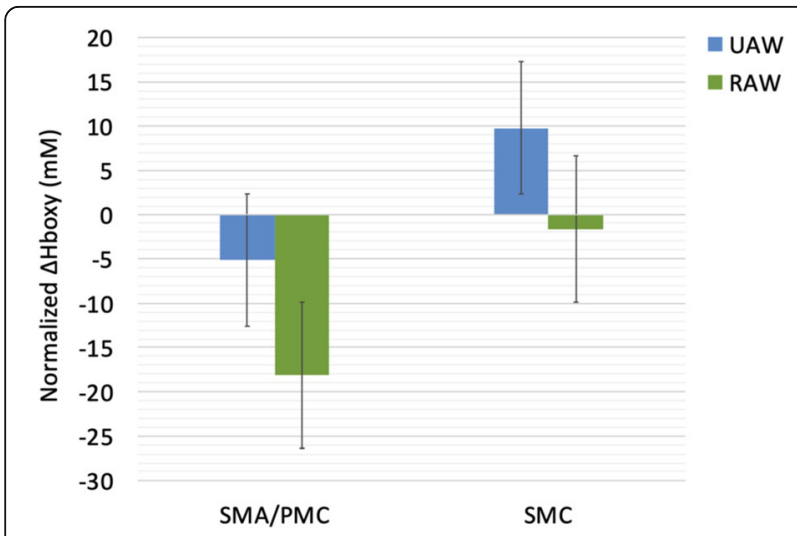

Fig. 3 Normalized oxygenated hemoglobin (Hboxy; mean \pm SME) for unassisted-walking (UAW) and robot-assisted walking (RAW). SMA/ PMC, supplementary motor area/premotor cortex; SMC, sensorimotor cortex; SME = standard mean error

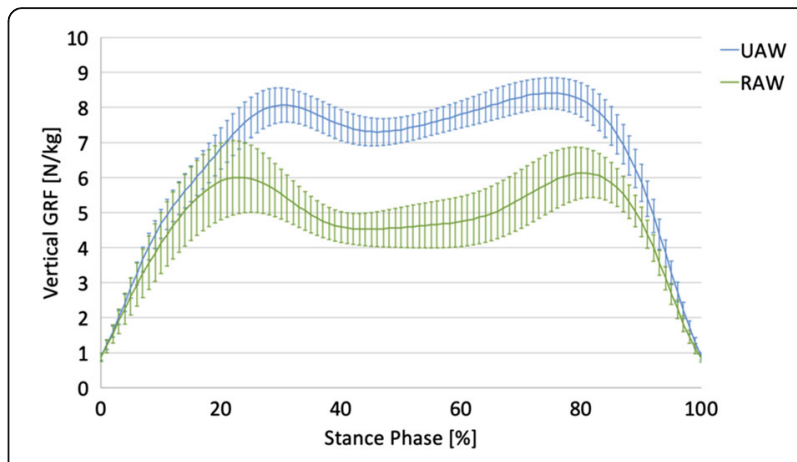

Fig. 4 Normalized vertical ground reaction force (GRF; mean $\pm S D$ ) during the stance phase of unassisted walking (UAW) and robotassisted walking (RAW). In Additional file 1, normalized vertical GRF during the stance phase of UAW (Figure S1) and RAW (Figure S2) are presented for each individual participant

were found during UAW or for other brain regions (SMA/PMC $p=0.951, r=0.020$ ). Thus, increased gait variability during RAW was associated with increased brain activity in the SMC (Fig. 5b).

\section{Discussion}

In this study, the effects of RA on cortical activity during TW and the relationship to changes in gait characteristics were investigated. We identified a classical double bump in the GRF, throughout the stance phase during both UAW and RAW, which was accompanied by significantly increased brain activity in the SMC compared to premotor/supplementary motor areas. However, individual analyses showed significantly higher inter- and intraindividual gait variability due to RA that correlated with increased hemodynamic activity in the SMC $(p=$ $0.052 ; r=0.570$ ).

In both conditions, shape characteristics of the mean GRF curves during the stance phase were observed. This in not in line with the results of Neckel et al. [46] who did not report a classical double bump during the stance phase during RAW, which could be due to the age differences of our samples. Furthermore, significantly altered kinematic patterns (lower GRF values and earlier and later appearances for the first and second vertical GRF peak values, respectively) as well as large inter- and intraindividual gait variability were observed during RAW compared to UAW. Results of the kinematic patterns are consistent with other biomechanical studies showing altered muscle activity [39, 42] or kinematic patterns [45-47] due to RA. The results of greater inter- and intraindividual gait variability during RAW do not agree with the more stereotypical and similar patterns of Gizzi et al. [49], nor with the assumption that the user lacks the ability to vary and adapt gait patterns during RAW [45, 48, 50]. 
Table 1 Comparison of vertical ground reaction force variables (GRF; mean \pm SD) during the stance phase of unassisted walking (UAW) and robot-assisted walking (RAW), SD = standard deviation

\begin{tabular}{|c|c|c|c|c|c|c|}
\hline Kinetic Gait Variable & UAW & RAW & t & df & p & r \\
\hline First Peak (weight acceptance) [N/kg] & $8.2 \pm 0.5$ & $6.2 \pm 1.0$ & 6.807 & 11 & 0.000 & 0.899 \\
\hline First Peak (weight acceptance) [\% Stance Phase] & $31.4 \pm 2.6$ & $24.8 \pm 3.2$ & 7.366 & 11 & 0.000 & 0.912 \\
\hline Valley (mid-stance) [N/kg] & $7.2 \pm 0.4$ & $4.2 \pm 0.6$ & 23.963 & 11 & 0.000 & 0.991 \\
\hline Valley (mid-stance) [\% Stance Phase] & $48.9 \pm 2.9$ & $49.6 \pm 6.3$ & -0.277 & 11 & 0.787 & 0.083 \\
\hline Second Peak (weight acceptance) [N/kg] & $8.6 \pm 0.4$ & $6.3 \pm 0.7$ & 12.898 & 11 & 0.000 & 0.968 \\
\hline Second Peak (weight acceptance) [\% Stance Phase] & $75.8 \pm 3.0$ & $82.4 \pm 2.3$ & -7.789 & 11 & 0.000 & 0.920 \\
\hline Intraindividual Variability [\%] & $5.8 \pm 1.4$ & $7.9 \pm 1.3$ & -4.427 & 11 & 0.001 & 0.800 \\
\hline Interindividual Variability [\%] & 7.0 & 15.7 & - & - & - & - \\
\hline Symmetry Index [\%] & $4.3 \pm 2.0$ & $7.7 \pm 2.7$ & -2.871 & 11 & 0.015 & 0.654 \\
\hline
\end{tabular}

Regarding brain activity during UAW, Hboxy concentration changes were significantly increased in sensorimotor areaes compared to areas of the SMA/PMC which is in line with other neurophysiological studies that showed increased Hboxy concentrations during walking $[57,58]$. This is further confirmed by EEG studies reporting suppressed alpha and beta oscillations within the SMC [60-62] during active walking. This also demonstrates that the SMC and the corticospinal tract contribute directly to muscle activity in locomotion [9, $53,63]$ representing a general marker of an active movemet-related neuronal state [61].

Analyzing the effects of RA on cortical patterns, significantly increased Hboxy concentration changes were also observed in SMC compared to frontal areas. Whereas Kim et al. [68] observed more global network activation during RAW compared to UAW, Knaepen et al. [36] reported significantly suppressed alpha and beta power during UAW compared to RAW with the conclusion that walking with $100 \%$ GF leads to less active participation and little activation of the SMC, which should be avoided during RAGT.

However, during RAW, we observed a positive correlation between $\triangle$ Hboxy concentrations in the SMC and intraindividual gait variability. Thus, individuals with larger gait variability showed higher sensorimotor brain activity, which is similar to the results reported of Vitorio et al. [41]. In this study, positive correlations between gait variability and $\triangle$ Hboxy in the PMC and M1 were found in young healthy adults when walking with rhythmic auditory cueing [41]. The following two possible explanations are suggested.

On one side, robotic guidance might induce additional and new sensory feedback that promotes active participation, resulting in high gait variability and increased brain activity. This possibility is supported by previous observations that muscles exhibited marked and structurally phased activity, even under full guidance conditions [39, 42, 86-88]. Van Kammen et al. [88] found muscle activity in the vastus lateralis, suggesting that the leg muscles are still activated during RAW as opposed to the muscles related to stability and propulsion, in which activity is reduced under guidance conditions. This finding is remarkable because, in this state, the exoskeleton is responsible for walking control, and theoretically, no voluntary activity from the performer is required $[87,89]$. However, the instructions used in the present study (i.e., 'actively move along with the device') may have affected activity, as previous studies have shown that encouraging active involvement increases muscle activity $[86,87]$ as well as brain activity significantly during RAW [64]. More specifically, Wagner et al.

Table 2 Comparison of temporal gait variables (mean \pm SD) during unassisted walking (UAW) and robot-assisted walking (RAW)

\begin{tabular}{llllll}
\hline Temporal Gait Variable & UAW & RAW & t & df & $p$ \\
\hline Stance Phase [s] & $0.84 \pm 0.05$ & $0.93 \pm 0.03$ & 5.78 & 11 & 0.000 \\
Initial Double-Limb Support [s] & $0.17 \pm 0.02$ & $0.19 \pm 0.03$ & 2.60 & 11 & 0.025 \\
Single Limb Support [s] & $0.50 \pm 0.04$ & $0.56 \pm 0.03$ & 4.82 & 11 & 0.001 \\
Terminal Double-Limb Support [s] & $0.17 \pm 0.02$ & $0.19 \pm 0.03$ & 2.78 & 11 & 0.018 \\
Swing Phase [s] & $0.50 \pm 0.04$ & $0.56 \pm 0.03$ & 4.89 & 11 & 0.617 \\
Steps [number] & $251.8 \pm 24.4$ & $189.1 \pm 10.2$ & 7.38 & 11 & 0.000 \\
Cadence [steps/min] & $91.1 \pm 5.0$ & $82.1 \pm 0.1$ & 6.03 & 11 & 0.000 \\
\hline
\end{tabular}



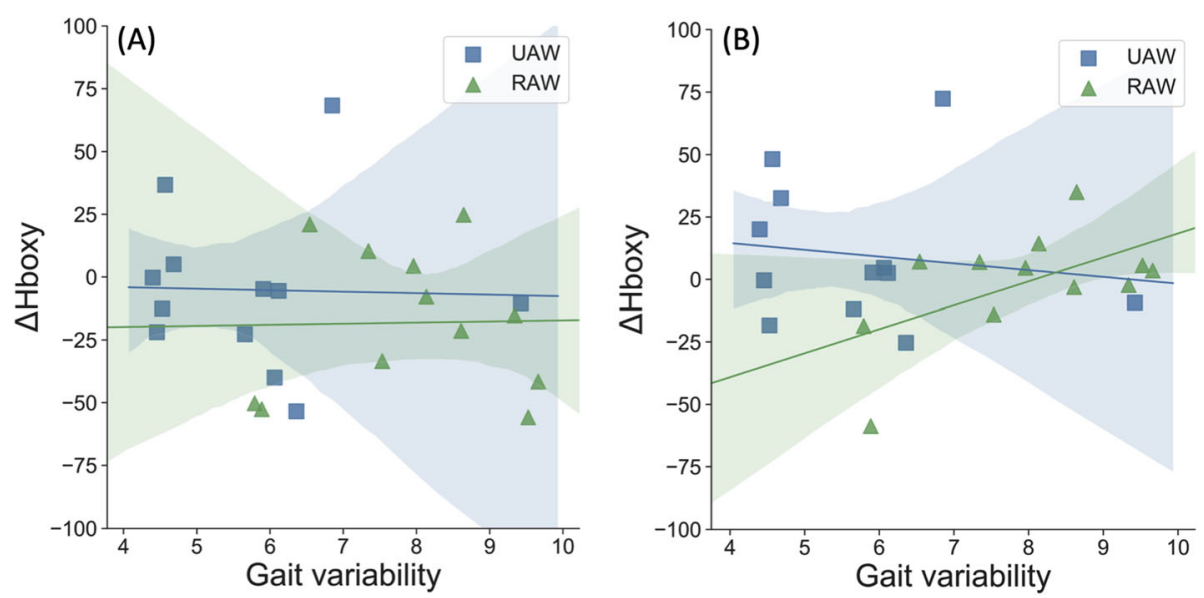

Fig. 5 Correlations between relative oxygenated hemoglobin (Hboxy) and gait variability calculated by intraindividual coefficient of variation (CV) during unassisted-walking (UAW) and robot-assisted walking (RAW). a SMA/PMC, supplementary motor area/premotor cortex; b SMC, sensorimotor cortex; the shaded area represents the $95 \%$ confidence interval

[64] showed significantly suppressed alpha and beta power during active compared to passive RAW. Dobkin (1994) also showed that passive stepping can lead to task-specific sensory information that induces and modulates step-like electromyography activity [90]. Thus, high guidance might also promote active contribution. Particularly in patients who are not able to walk unassisted, successful stepping induces task-specific sensory information that may trigger plastic changes in the central nervous system [88, 91]. Since active participation and the production of variable movement patterns are prerequisites for activity-dependent neuroplasticity $[7,20,89,92-94]$, it is important to determine whether the activation of the SMC can be triggered by changes in the levels of GF, BWS and kinematic freedom in order to specifically provoke gait variability due to active participation of the patient $[45,48,50]$. High gait variability may indicate that people use multiple combinations of gait variables to walk more effectively $[45,95]$, resulting in better and faster improvements during robotic rehabilitation.

On other side, the sensory feedback from robot guidance could also disturb the brain network underlying automatic walking, leading to increased gait variability and sensorimotor activity. According to Vitorio et al. [41], the requirement to adapt to external stimuli leads to disturbances in automatic walking in young healthy people, resulting in higher gait variability and higher cortical costs. As previous study have shown, the ability to execute a physiological gait pattern depends on how the training parameters such as BWS, GF or kinematic freedom in the robotic devices are set. During RAW with fixed pelvis, significantly altered muscle activity $[39,42,45]$ and kinematic patterns $[48,50]$ were found. In addition to GF, BWS and kinematic freedom, the presence of foot support may also contribute to altered patterns. The safety procedures of the therapy institution required that all subjects wear straps around the front foot to assist with ankle dorsiflexion, which is known to reduce activity in the ankle dorsiflexors $[39,42]$.

In summary, increased gait variability and sensorimotor activity during RAW could be the result of active participation or disrupted automatic locomotor control. However, the generalization of these results to other populations is not intended or recommended. Healthy elderly individuals [41] and patients with stroke [22], multiple sclerosis [23, 25, 26], Parkinson's disease [27, 28], brain injuries [29] or spinal cord injuries [30,31] who suffer from gait and balance disorders react differently to robotic support than healthy young people, which may lead to different gait and brain activation patterns [44]. In addition to high inter- and intraindividual variability within one sample, the heterogeneity of methodological procedures between studies appears to pose another challenge [71].

Therefore, one future goal should be to understand the mechanisms underlying RAGT and which parameters determine the effectiveness of a single treatment in the heterogenuous population of patients suffering from neurological diseases [37]. For this purpose, objective biomarkers for motor recovery and neuroplastic changes have to be identified [37]. Then, specific training protocols and further interventions, such as augmented feedback with virtual reality, brainmachine interface or non-invasive brain stimulation, can be developed to deliver sustainable therapies for individualized rehabilitation that optimizes the outcome and efficacy of gait recovery, which together can foster independent living and improve the quality of life for neurological patients [37, 71]. 


\section{Methodological limitations}

Two methodological limitations that emerged using the present approach should be mentioned. First, the ability to walk is guided by an optimal interaction between cortical and subcortical brain structures within the locomotor network [53]. Using our NIRSport system, we were only able to report brain activity patterns in motor cortical areas and were unable to monitor the activities of subcortical areas or other cortical involvements. Various studies have reported that patients with gait disorders recruit additional cortical regions to manage the demands of UAW and RAW, due to structural and/or functional changes in the brain. Measuring the entire cortical network underlying locomotion may be necessary to investigate neuronal compensations and cognitive resources used for neuroplastic processes during gait rehabilitation. Therefore, we must be careful when discussing brain activity associated with other regions involved in locomotor control [9].

Secondly, we must take into account the small sample size of our healthy volunteers and their young age (mean: $25 \pm 4$ years), which also had no gait pathologies. Thus, RA guidance of gait movement might have different effects in elderly subjects or patients who are not able to walk without restrictions [96]. Therefore, the findings from our study are difficult to apply to other age or patient groups, as neurological patients often suffer from movement disorders and therefore use different control strategies during RAW. Although the available results provide relevant insights into the mobile applications of neurophysiological measurements during RAW, with approaches for further therapeutic interventions during robotic rehabilitation, the effects of RAW must also be investigated in other groups and in patients with gait disorders in the future.

\section{Conclusions}

The purpose of the present study was to investigate brain activity during UAW and RAW and how this activity was associated with gait characteristics. The results confirmed the involvement of the SMC during TW and significantly increased gait variability due to RA, which correlated positively with brain activity. Furthermore, this study highlights the interaction between cortical activity and gait variability, stressing the need to use holistic, multisystem approaches when investigating TW in elderly individuals or patients suffering from gait disorders. Assessing the effects of RA on brain activity and gait characteristics is essential to develop a better understanding of how robotic devices affect human locomotion. This knowledge is essential for interventional studies examining the rehabilitation of motor disorders. Basic research regarding robotic rehabilitation is necessary to gain a deeper understanding of the brain and gait patterns associated with RAW, which is essential for further investigations of gait recovery and neuroplastic changes. In addition, clinical longitudinal studies are required to identify individual gait improvements and to identify the underlying neurophysiological changes to develop therapies with respect to interindividual differences. RAGT devices should be designed to provide an amount of force that adapts to the patient's capacity, to achieve an optimal balance between forced motor activity and the promotion of the patient's voluntary activity [36, 92-94]. Further combined studies are necessary to determine the relationship between brain activity and functional motor improvements and to evaluate the effects of therapeutic interventions. Neurophysiological investigations can contribute to the development of robotic rehabilitation and to individual, closed-loop treatments for future neurorehabilitation therapies.

\section{Supplementary information}

Supplementary information accompanies this paper at https://doi.org/10. 1186/s12984-019-0636-3.

Additional file 1: Figure S1. Normalized vertical ground reaction force (GRF; mean) during the stance phase of unassisted walking (UAW) for each individual participant. Figure S2. Normalized vertical ground reaction force (GRF; mean) during the stance phase of robot-assisted walking (RAW) for each individual participant.

\section{Abbreviations \\ ANOVA: Analysis of variance; BA: Brodmann area; BWS: Body weight support; EEG: Electroencephalography; fNIRS: Functional nearinfrared spectroscopy; GF: Guidance force; GRF: Ground reaction forces; Hbdeoxy: Deoxygenated hemoglobin; Hboxy: Oxygenated hemoglobin; M1: Primary motor cortex; RA: Robotic assistance; RAGT: Robot assisted gait training; RAW: Robot assisted walking; ROI: Regions of interest; SD: Standard deviation; SEM: Standard mean error; SI: Symmetry index; SMA: Supplementary motor area; SMC: Sensorimotor cortex; TW: Treadmill walking; UAW: Unassisted walking; $\Delta$ Hboxy: Relative changes of oxygenated hemoglobin}

\section{Acknowledgments}

We thank Alina Hammer and Svenja Klink for assisting with the data collection, and Elmo Neuberger and Alexander Stahl for preparing the graphics included in this manuscript.

\section{Authors' contribution}

$A B$ : Research project conception and execution, data acquisition, statistical analysis, interpretation and the manuscript writing. $A B$ acts as the corresponding author. $\mathrm{FH}$ : Research project conception and execution, data acquisition, statistical analysis, and interpretation. CM: Research project conception. FS, FT, WS, and MD: Research project conception, manuscript review, and critique. All authors read and approved the final version of the manuscript.

\section{Funding}

Not applicable.

\section{Availability of data and materials}

The datasets used and analysed during the current study are available from the corresponding author on reasonable request.

Ethics approval and consent to participate

The study was performed in accordance with the Declaration of Helsinki. Experimental procedures were performed in accordance with the recommendations of the Deutsche Gesellschaft für Psychologie and were 
approved by the ethical committee of the Medical Association Hessen in Frankfurt (Germany). Participants were informed of all relevant issues regarding the study and provided their written informed consent prior to the initiation of the experiment.

\section{Consent for publication}

Consent from all authors has been acquired prior to submission of this article.

\section{Competing interests}

The authors declare that they have no competing interests.

\section{Author details}

${ }^{1}$ Department of Sport Psychology, Institute of Sport Science, Johannes Gutenberg-University Mainz, Albert Schweitzer Straße 22, 55128 Mainz, Germany. ${ }^{2}$ Department of Training and Movement Science, Institute of Sport Science, Johannes Gutenberg-University Mainz, Mainz, Germany. ${ }^{3}$ School of Kinesiology, Louisiana State University, Baton Rouge, USA. ${ }^{4}$ Center of Neurorehabilitation neuroneum, Bad Homburg, Germany. ${ }^{5}$ Centre for Cognitive Neuroscience, Paris Lodron University of Salzburg, Salzburg, Austria.

\section{Received: 20 August 2019 Accepted: 13 December 2019}

\section{Published online: 27 December 2019}

\section{References}

1. Verghese J, LeValley A, Hall CB, Katz MJ, Ambrose AF, Lipton RB. Epidemiology of gait disorders in community-residing older adults. J Am Geriatr Soc. 2006;54:255-61. https://doi.org/10.1111/j.1532-5415.2005. 00580.x.

2. Forte R, Boreham CAG, de Vito G, Pesce C. Health and quality of life perception in older adults: the joint role of cognitive efficiency and functional mobility. Int J Environ Res Public Health. 2015;12:11328-44. https://doi.org/10.3390/ijerph120911328

3. Fagerström C, Borglin G. Mobility, functional ability and health-related quality of life among people of 60 years or older. Aging Clin Exp Res. 2010; 22:387-94.

4. Hirsch CH, Buzková P, Robbins JA, Patel KV, Newman AB. Predicting late-life disability and death by the rate of decline in physical performance measures. Age Ageing. 2012;41:155-61. https://doi.org/10. 1093/ageing/afr151.

5. Soh S-E, Morris ME, McGinley JL. Determinants of health-related quality of life in Parkinson's disease: a systematic review. Parkinsonism Relat Disord. 2011;17:1-9. https://doi.org/10.1016/j.parkreldis.2010.08.012.

6. Nielsen JB. How we walk: central control of muscle activity during human walking. Neuroscientist. 2003:9:195-204. https://doi.org/10.1177/ 1073858403009003012

7. Bernstein $\mathrm{N}$. The co-ordination and regulation of movements. 1st ed. Oxford: Pergamon Press; 1967.

8. Hatze H. Motion variability--its definition, quantification, and origin. J Mot Behav. 1986;18:5-16

9. La Fougère $C$, Zwergal A, Rominger A, Förster S, Fesl G, Dieterich $M$, et al. Real versus imagined locomotion: a 18F-FDG PET-fMRI comparison. Neuroimage. 2010;50:1589-98. https://doi.org/10.1016/j. neuroimage.2009.12.060

10. Ellis T, Cavanaugh JT, Earhart GM, Ford MP, Foreman KB, Dibble LE. Which measures of physical function and motor impairment best predict quality of life in Parkinson's disease? Parkinsonism Relat Disord. 2011;17:693-7. https:// doi.org/10.1016/j.parkreldis.2011.07.004.

11. Schmid A, Duncan PW, Studenski S, Lai SM, Richards L, Perera S, Wu SS. Improvements in speed-based gait classifications are meaningful. Stroke. 2007;38:2096-100. https://doi.org/10.1161/STROKEAHA.106.475921.

12. von Schroeder HP, Coutts RD, Lyden PD, Billings E, Nickel VL. Gait parameters following stroke: a practical assessment. J Rehabil Res Dev. 1995; 32:25-31.

13. Stergiou N, Harbourne R, Cavanaugh J. Optimal movement variability: a new theoretical perspective for neurologic physical therapy. J Neurol Phys Ther. 2006:30:120-9. https://doi.org/10.1097/01.npt.0000281949.48193.d9.

14. Hausdorff JM. Gait dynamics, fractals and falls: finding meaning in the stride-to-stride fluctuations of human walking. Hum Mov Sci. 2007:26:55589. https://doi.org/10.1016/j.humov.2007.05.003.
15. Chen G, Patten C, Kothari DH, Zajac FE. Gait differences between individuals with post-stroke hemiparesis and non-disabled controls at matched speeds Gait Posture. 2005;22:51-6. https://doi.org/10.1016/j.gaitpost.2004.06.009.

16. Titianova EB, Tarkka IM. Asymmetry in walking performance and postural sway in patients with chronic unilateral cerebral infarction. J Rehabil Res Dev. 1995:32:236-44.

17. Turner DL, Ramos-Murguialday A, Birbaumer N, Hoffmann U, Luft A. Neurophysiology of robot-mediated training and therapy: a perspective for future use in clinical populations. Front Neurol. 2013:4:184. https://doi.org/ 10.3389/fneur.2013.00184.

18. Calabrò RS, Cacciola A, Bertè F, Manuli A, Leo A, Bramanti A, et al. Robotic gait rehabilitation and substitution devices in neurological disorders: where are we now? Neurol Sci. 2016:37:503-14. https://doi.org/10.1007/s10072016-2474-4

19. Galen SS, Clarke CJ, Allan DB, Conway BA. A portable gait assessment too to record temporal gait parameters in SCI. Med Eng Phys. 2011;33:626-32. https://doi.org/10.1016/j.medengphy.2011.01.003.

20. Schmidt RA, Lee TD. Motor control and learning: A behavioral emphasis. 5th ed. Champaign: Human Kinetics; 2011.

21. Bruni MF, Melegari C, de Cola MC, Bramanti A, Bramanti P, Calabrò RS. What does best evidence tell us about robotic gait rehabilitation in stroke patients: a systematic review and meta-analysis. J Clin Neurosci. 2018;48:117. https://doi.org/10.1016/j.jocn.2017.10.048.

22. Mehrholz J, Thomas S, Werner C, Kugler J, Pohl M, Elsner B. Electromechanical-assisted training for walking after stroke. Cochrane Database Syst Rev. 2017;5:CD006185. https://doi.org/10.1002/14651858. CD006185.pub4

23. Beer S, Aschbacher B, Manoglou D, Gamper E, Kool J, Kesselring J. Robotassisted gait training in multiple sclerosis: a pilot randomized trial. Mult Scler. 2008;14:231-6. https://doi.org/10.1177/1352458507082358.

24. Lo AC, Triche EW. Improving gait in multiple sclerosis using robot-assisted, body weight supported treadmill training. Neurorehabil Neural Repair. 2008; 22:661-71. https://doi.org/10.1177/1545968308318473.

25. Schwartz I, Sajin A, Moreh E, Fisher I, Neeb M, Forest A, et al. Robot-assisted gait training in multiple sclerosis patients: a randomized trial. Mult Scler. 2012:18:881-90. https://doi.org/10.1177/1352458511431075.

26. Straudi S, Fanciullacci C, Martinuzzi C, Pavarelli C, Rossi B, Chisari C, Basaglia $\mathrm{N}$. The effects of robot-assisted gait training in progressive multiple sclerosis: a randomized controlled trial. Mult Scler. 2016;22:373-84. https:// doi.org/10.1177/1352458515620933.

27. Lo AC, Chang VC, Gianfrancesco MA, Friedman JH, Patterson TS, Benedicto DF. Reduction of freezing of gait in Parkinson's disease by repetitive robotassisted treadmill training: a pilot study. J Neuroeng Rehabil. 2010;7:51. https://doi.org/10.1186/1743-0003-7-51.

28. Picelli A, Melotti C, Origano F, Waldner A, Fiaschi A, Santilli V, Smania N. Robot-assisted gait training in patients with Parkinson disease: a randomized controlled trial. Neurorehabil Neural Repair. 2012:26:353-61. https://doi.org/10.1177/1545968311424417.

29. Esquenazi A, Lee S, Packel AT, Braitman L. A randomized comparative study of manually assisted versus robotic-assisted body weight supported treadmill training in persons with a traumatic brain injury. PM R. 2013:5:28090. https://doi.org/10.1016/j.pmrj.2012.10.009.

30. Nam KY, Kim HJ, Kwon BS, Park J-W, Lee HJ, Yoo A. Robot-assisted gait training (Lokomat) improves walking function and activity in people with spinal cord injury: a systematic review. J Neuroeng Rehabil. 2017:14:24. https://doi.org/10.1186/s12984-017-0232-3.

31. Schwartz I, Sajina A, Neeb M, Fisher I, Katz-Luerer M, Meiner Z. Locomotor training using a robotic device in patients with subacute spinal cord injury. Spinal Cord. 2011;49:1062-7. https://doi.org/10.1038/sc.2011.59.

32. Wirz M, Zemon DH, Rupp R, Scheel A, Colombo G, Dietz V, Hornby TG. Effectiveness of automated locomotor training in patients with chronic incomplete spinal cord injury: a multicenter trial. Arch Phys Med Rehabil. 2005;86:672-80. https://doi.org/10.1016/j.apmr.2004.08.004.

33. Benito-Penalva J, Edwards DJ, Opisso E, Cortes M, Lopez-Blazquez R, Murillo $\mathrm{N}$, et al. Gait training in human spinal cord injury using electromechanical systems: effect of device type and patient characteristics. Arch Phys Med Rehabil. 2012;93:404-12. https://doi.org/10.1016/j.apmr.2011.08.028.

34. Uçar DE, Paker N, Buğdaycı D. Lokomat: a therapeutic chance for patients with chronic hemiplegia. NeuroRehabil. 2014;34:447-53. https://doi.org/10 3233/NRE-141054 
35. Husemann B, Müller F, Krewer C, Heller S, Koenig E. Effects of locomotion training with assistance of a robot-driven gait orthosis in hemiparetic patients after stroke: a randomized controlled pilot study. Stroke. 2007;38: 349-54. https://doi.org/10.1161/01.STR.0000254607.48765.cb.

36. Knaepen K, Mierau A, Swinnen E, Fernandez Tellez H, Michielsen M, Kerckhofs $\mathrm{E}$, et al. Human-robot interaction: does robotic guidance force affect gait-related brain dynamics during robot-assisted treadmill walking? PLoS One. 2015;10:e0140626. https://doi.org/10.1371/journal.pone.0140626.

37. Coscia M, Wessel MJ, Chaudary U, Millán JDR, Micera S, Guggisberg A, et al. Neurotechnology-aided interventions for upper limb motor rehabilitation in severe chronic stroke. Brain. 2019;142:2182-97. https://doi.org/10.1093/brain/awz181.

38. Mehrholz J, Pohl M, Platz T, Kugler J, Elsner B. Electromechanical and robotassisted arm training for improving activities of daily living, arm function, and arm muscle strength after stroke. Cochrane Database Syst Rev. 2018;9: CD006876. https://doi.org/10.1002/14651858.CD006876.pub5.

39. Moreno JC, Barroso F, Farina D, Gizzi L, Santos C, Molinari M, Pons JL. Effects of robotic guidance on the coordination of locomotion. J Neuroeng Rehabil. 2013;10:79. https://doi.org/10.1186/1743-0003-10-79.

40. Youssofzadeh V, Zanotto D, Stegall P, Naeem M, Wong-Lin K, Agrawal SK, Prasad G. Directed neural connectivity changes in robot-assisted gait training: a partial granger causality analysis. Conf Proc IEEE Eng Med Biol Soc. 2014;2014:6361-4. https://doi.org/10.1109/EMBC.2014.6945083.

41. Vitorio R, Stuart S, Gobbi LTB, Rochester L, Alcock L, Pantall A. Reduced gait variability and enhanced brain activity in older adults with auditory cues: a functional near-infrared spectroscopy study. Neurorehabil Neural Repair. 2018;32:976-87. https://doi.org/10.1177/1545968318805159.

42. Hidler JM, Wall AE. Alterations in muscle activation patterns during roboticassisted walking. Clin Biomech (Bristol, Avon). 2005;20:184-93. https://doi. org/10.1016/j.clinbiomech.2004.09.016.

43. Hidler J, Nichols D, Pelliccio M, Brady K, Campbell DD, Kahn JH, Hornby TG. Multicenter randomized clinical trial evaluating the effectiveness of the Lokomat in subacute stroke. Neurorehabil Neural Repair. 2009;23:5-13. https://doi.org/10.1177/1545968308326632.

44. van Kammen K, Boonstra AM, van der Woude LHV, Reinders-Messelink HA, den Otter R. The combined effects of guidance force, bodyweight support and gait speed on muscle activity during able-bodied walking in the Lokomat. Clin Biomech (Bristol, Avon). 2016;36:65-73. https://doi.org/10. 1016/j.clinbiomech.2016.04.013.

45. Hidler J, Wisman W, Neckel N. Kinematic trajectories while walking within the Lokomat robotic gait-orthosis. Clin Biomech (Bristol, Avon). 2008;23: 1251-9. https://doi.org/10.1016/j.clinbiomech.2008.08.004.

46. Neckel ND, Blonien N, Nichols D, Hidler J. Abnormal joint torque patterns exhibited by chronic stroke subjects while walking with a prescribed physiological gait pattern. J Neuroeng Rehabil. 2008;5:19. https://doi.org/10. 1186/1743-0003-5-19.

47. Neckel N, Wisman W, Hidler J. Limb alignment and kinematics inside a Lokomat robotic orthosis. Conf Proc IEEE Eng Med Biol Soc. 2006;1:2698701. https://doi.org/10.1109/IEMBS.2006.259970.

48. Aurich-Schuler T, Gut A, Labruyère R. The FreeD module for the Lokomat facilitates a physiological movement pattern in healthy people - a proof of concept study. J Neuroeng Rehabil. 2019;16:26. https://doi.org/10.1186/ s12984-019-0496-X.

49. Gizzi L, Nielsen JF, Felici F, Moreno JC, Pons JL, Farina D. Motor modules in robot-aided walking. J Neuroeng Rehabil. 2012;9:76. https://doi.org/10.1186/ 1743-0003-9-76.

50. Aurich-Schuler T, Labruyère R. An increase in kinematic freedom in the Lokomat is related to the ability to elicit a physiological muscle activity pattern: a secondary data analysis investigating differences between guidance force, path control, and FreeD. Front Robot Al. 2019;6:387. https:// doi.org/10.3389/frobt.2019.00109.

51. Chen $\mathbf{H}-\mathrm{H}$, Yang $Y-R$, Lu C-F, Wang R-Y. Novel gait training alters functional brain connectivity during walking in chronic stroke patients: a randomized controlled pilot trial. J Neuroeng Rehabil. 2019;16:33. https://doi.org/10. 1186/s12984-019-0503-2

52. Cutini S, Brigadoi S. Unleashing the future potential of functional nearinfrared spectroscopy in brain sciences. J Neurosci Methods. 2014;232:152-6. https://doi.org/10.1016/j.jneumeth.2014.05.024.

53. Herold F, Wiegel P, Scholkmann F, Thiers A, Hamacher D, Schega L. Functional near-infrared spectroscopy in movement science: a systematic review on cortical activity in postural and walking tasks. Neurophotonics. 2017:4:41403. https://doi.org/10.1117/1.NPh.4.4.041403.
54. Quaresima V, Ferrari M. Functional near-infrared spectroscopy (fNIRS) for assessing cerebral cortex function during human behavior in natural/social situations: a concise review. Organ Res Methods. 2019;22:46-68. https://doi. org/10.1177/1094428116658959.

55. Koch SP, Koendgen S, Bourayou R, Steinbrink J, Obrig H. Individual alphafrequency correlates with amplitude of visual evoked potential and hemodynamic response. Neuroimage. 2008;41:233-42. https://doi.org/10. 1016/j.neuroimage.2008.02.018.

56. Ferrari M, Mottola L, Quaresima V. Principles, techniques, and limitations of near infrared spectroscopy. Can J Appl Physiol. 2004;29:463-87.

57. Miyai I, Tanabe HC, Sase I, Eda H, Oda I, Konishi I, et al. Cortical mapping of gait in humans: a near-infrared spectroscopic topography study. Neuroimage. 2001;14:1186-92. https://doi.org/10.1006/nimg.2001.0905.

58. Hamacher D, Herold F, Wiegel P, Hamacher D, Schega L. Brain activity during walking: a systematic review. Neurosci Biobehav Rev. 2015;57:310-27. https://doi.org/10.1016/j.neubiorev.2015.08.002.

59. Koenraadt KLM, Roelofsen EGJ, Duysens J, Keijsers NLW. Cortical control of normal gait and precision stepping: an fNIRS study. Neuroimage. 2014;85(Pt 1):415-22. https://doi.org/10.1016/j.neuroimage.2013.04.070

60. Severens M, Nienhuis B, Desain P, Duysens J. Feasibility of measuring event related desynchronization with electroencephalography during walking. Conf Proc IEEE Eng Med Biol Soc. 2012;2012:2764-7. https://doi.org/10.1109/ EMBC.2012.6346537.

61. Seeber M, Scherer R, Wagner J, Solis-Escalante T, Müller-Putz GR. EEG beta suppression and low gamma modulation are different elements of human upright walking. Front Hum Neurosci. 2014;8:485. https://doi.org/10.3389/ fnhum.2014.00485.

62. Bulea TC, Kim J, Damiano DL, Stanley CJ, Park H-S. Prefrontal, posterior parietal and sensorimotor network activity underlying speed control during walking. Front Hum Neurosci. 2015;9:247. https://doi.org/10.3389/fnhum. 2015.00247

63. Petersen TH, Willerslev-Olsen M, Conway BA, Nielsen JB. The motor cortex drives the muscles during walking in human subjects. J Physiol Lond. 2012; 590:2443-52. https://doi.org/10.1113/jphysiol.2012.227397.

64. Wagner J, Solis-Escalante T, Grieshofer P, Neuper C, Müller-Putz G, Scherer R. Level of participation in robotic-assisted treadmill walking modulates midline sensorimotor EEG rhythms in able-bodied subjects. Neuroimage. 2012;63:1203-11. https://doi.org/10.1016/j.neuroimage.2012.08.019.

65. Wagner J, Solis-Escalante T, Scherer R, Neuper C, Müller-Putz G. It's how you get there: walking down a virtual alley activates premotor and parietal areas. Front Hum Neurosci. 2014;8:93. https://doi.org/10.3389/fnhum.2014. 00093.

66. Wagner J, Solis-Escalante T, Neuper C, Scherer R, Müller-Putz G. Robot assisted walking affects the synchrony between premotor and somatosensory areas. Biomed Tech (Berl). 2013. https://doi.org/10.1515/bmt2013-4434.

67. Seeber M, Scherer R, Wagner J, Solis-Escalante T, Müller-Putz GR. High and low gamma EEG oscillations in central sensorimotor areas are conversely modulated during the human gait cycle. Neuroimage. 2015;112:318-26. https://doi.org/10.1016/j.neuroimage.2015.03.045.

68. Kim HY, Yang SP, Park GL, Kim EJ, You JSH. Best facilitated cortical activation during different stepping, treadmill, and robot-assisted walking training paradigms and speeds: a functional near-infrared spectroscopy neuroimaging study. NeuroRehabilitation. 2016;38:171-8. https://doi.org/10. 3233/NRE-161307.

69. Simis M, Santos K, Sato J, Fregni F, Battistella L. T107. Using Functional Near Infrared Spectroscopy (fNIRS) to assess brain activity of spinal cord injury patient, during robot-assisted gait. Clin Neurophysiol. 2018;129:e43-4. https://doi.org/10.1016/j.clinph.2018.04.108.

70. Calabrò RS, Naro A, Russo M, Bramanti P, Carioti L, Balletta T, et al. Shaping neuroplasticity by using powered exoskeletons in patients with stroke: a randomized clinical trial. J Neuroeng Rehabil. 2018;15:35. https://doi.org/10. 1186/s12984-018-0377-8

71. Berger A, Horst F, Müller S, Steinberg F, Doppelmayr M. Current state and future prospects of EEG and fNIRS in robot-assisted gait rehabilitation: a brief review. Front Hum Neurosci. 2019;13:172. https://doi.org/10.3389/ fnhum.2019.00172.

72. Tucker MR, Olivier J, Pagel A, Bleuler H, Bouri M, Lambercy O, et al. Control strategies for active lower extremity prosthetics and orthotics: a review. J Neuroeng Rehabil. 2015;12:1. https://doi.org/10.1186/1743-0003-12-1. 
73. Oldfield RC. The assessment and analysis of handedness: the Edinburgh inventory. Neuropsychologia. 1971;9:97-113. https://doi.org/10.1016/00283932(71)90067-4

74. Colombo G, Joerg M, Schreier R, Dietz V. Treadmill training of paraplegic patients using a robotic orthosis. J Rehabil Res Dev. 2000;37:693-700.

75. Duschau-Wicke A, Caprez A, Riener R. Patient-cooperative control increases active participation of individuals with $\mathrm{SCl}$ during robot-aided gait training J Neuroeng Rehabil. 2010;7:43. https://doi.org/10.1186/1743-0003-7-43.

76. Obrig $\mathrm{H}$, Villringer $\mathrm{A}$. Beyond the visible--imaging the human brain with light. J Cereb Blood Flow Metab. 2003;23:1-18. https://doi.org/10.1097/01. WCB.0000043472.45775.29.

77. Jurcak V, Tsuzuki D, Dan I. 10/20, 10/10, and 10/5 systems revisited: their validity as relative head-surface-based positioning systems. Neuroimage. 2007;34:1600-11. https://doi.org/10.1016/j.neuroimage.2006.09.024.

78. Vitorio R, Stuart S, Rochester L, Alcock L, Pantall A. fNIRS response during walking - Artefact or cortical activity? A systematic review. Neurosci Biobehav Rev. 2017;83:160-72. https://doi.org/10.1016/j. neubiorev.2017.10.002

79. Xu Y, Graber HL, Barbour RL. nirsLAB: A Computing Environment for fNIRS Neuroimaging Data Analysis. Miami: Optical Society of America; 2014. p. 1. https://doi.org/10.1364/BIOMED.2014.BM3A.1.

80. Sassaroli A, Fantini S. Comment on the modified Beer-Lambert law for scattering media. Phys Med Biol. 2004;49:N255-7. https://doi.org/10.1088/ 0031-9155/49/14/N07.

81. Cope M, Delpy DT, Reynolds EO, Wray S, Wyatt J, van der Zee P. Methods of quantitating cerebral near infrared spectroscopy data. Adv Exp Med Biol. 1988;222:183-9. https://doi.org/10.1007/978-1-4615-9510-6_21.

82. Suzuki M, Miyai I, Ono T, Oda I, Konishi I, Kochiyama T, Kubota K. Prefrontal and premotor cortices are involved in adapting walking and running speed on the treadmill: an optical imaging study. Neuroimage. 2004;23:1020-6. https://doi.org/10.1016/j.neuroimage.2004.07.002.

83. Strangman G, Culver JP, Thompson JH, Boas DA. A quantitative comparison of simultaneous BOLD FMRI and NIRS recordings during functional brain activation. Neuroimage. 2002;17:719-31.

84. Winter DA. Kinematic and kinetic patterns in human gait: variability and compensating effects. Hum Mov Sci. 1984;3:51-76. https://doi.org/10.1016/ 0167-9457(84)90005-8.

85. Herzog W, Nigg BM, Read LJ, Olsson E. Asymmetries in ground reaction force patterns in normal human gait. Med Sci Sports Exerc. 1989;21:110-4.

86. Aurich Schuler T, Müller R, van Hedel HJA. Leg surface electromyography patterns in children with neuro-orthopedic disorders walking on a treadmill unassisted and assisted by a robot with and without encouragement. J Neuroeng Rehabil. 2013;10:78. https://doi.org/ 10.1186/1743-0003-10-78

87. Israel JF, Campbell DD, Kahn JH, Hornby TG. Metabolic costs and muscle activity patterns during robotic- and therapist-assisted treadmill walking in individuals with incomplete spinal cord injury. Phys Ther. 2006;86:1466-78. https://doi.org/10.2522/ptj.20050266.

88. van Kammen K, Boonstra AM, van der Woude LHV, Reinders-Messelink HA, den Otter R. Differences in muscle activity and temporal step parameters between Lokomat guided walking and treadmill walking in post-stroke hemiparetic patients and healthy walkers. J Neuroeng Rehabil. 2017;14:32. https://doi.org/10.1186/s12984-017-0244-z

89. Duschau-Wicke A, von Zitzewitz J, Caprez A, Lunenburger L, Riener R. Path control: a method for patient-cooperative robot-aided gait rehabilitation. IEEE Trans Neural Syst Rehabil Eng. 2010;18:38-48. https://doi.org/10.1109/ TNSRE.2009.2033061.

90. Dobkin BH, Harkema S, Requejo P, Edgerton VR. Modulation of locomotorlike EMG activity in subjects with complete and incomplete spinal cord injury. Neurorehabil Neural Repair. 1995;9:183-90.

91. Riener R, Lünenburger $L$, Jezernik S, Anderschitz M, Colombo G, Dietz V. Patient-cooperative strategies for robot-aided treadmill training: first experimental results. IEEE Trans Neural Syst Rehabil Eng. 2005;13:380-94. https://doi.org/10.1109/TNSRE.2005.848628.

92. Riener R, Lünenburger L, Maier I, Colombo G, Dietz V. Locomotor training in subjects with Sensori-motor deficits: an overview of the robotic gait Orthosis Lokomat. J Healthc Eng. 2010;1:197-216. https://doi.org/10.1260/ 2040-2295.1.2.197.

93. Lewek MD, Cruz TH, Moore JL, Roth HR, Dhaher YY, Hornby TG. Allowing intralimb kinematic variability during locomotor training poststroke improves kinematic consistency: a subgroup analysis from a randomized clinical trial. Phys Ther. 2009;89:829-39. https://doi.org/10.2522/ptj.20080180.

94. Krishnan C, Kotsapouikis D, Dhaher YY, Rymer WZ. Reducing robotic guidance during robot-assisted gait training improves gait function: a case report on a stroke survivor. Arch Phys Med Rehabil. 2013;94:1202-6. https:// doi.org/10.1016/j.apmr.2012.11.016.

95. Bohnsack-McLagan NK, Cusumano JP, Dingwell JB. Adaptability of stride-tostride control of stepping movements in human walking. J Biomech. 2016; 49:229-37. https://doi.org/10.1016/j.jbiomech.2015.12.010.

96. Yang JK, Ahn NE, Kim DH, Kim DY. Plantar pressure distribution during robotic-assisted gait in post-stroke hemiplegic patients. Ann Rehabil Med. 2014;38:145-52. https://doi.org/10.5535/arm.2014.38.2.145.

\section{Publisher's Note}

Springer Nature remains neutral with regard to jurisdictional claims in published maps and institutional affiliations.
Ready to submit your research? Choose BMC and benefit from:

- fast, convenient online submission

- thorough peer review by experienced researchers in your field

- rapid publication on acceptance

- support for research data, including large and complex data types

- gold Open Access which fosters wider collaboration and increased citations

- maximum visibility for your research: over $100 \mathrm{M}$ website views per year

At BMC, research is always in progress.

Learn more biomedcentral.com/submissions 